"The claim made for it"-the cold bath-" that it reduces the mortality from 17 or 18 to 8 or 9 per cent., has not been disproved." I would go further, and submit that the claim has been proved as thoroughly as it is possible to prove the success of any therapeutic measure. The many thousands of consecutive cases recorded on the Continent, in the United States, Canada, and Australia, and treated without selection, show an average mortality well below 8 per cent.

Dr. Phillips advances one rather unusual argument in defence of the omission to practise systematic cold bathing in this country. Taking roo cases, it may be admitted that on the average 82 would recover even without cold bathing, while 9 would die even with the bath. Therefore he concludes that. " 91 of every 100 patients are subjected to repeated bathings unnecessarily, and that the 9 who die have these repeated bathings added to their sufferings." This line of argument might be applied to any form of treatment that is not invariably successful. Supposing it to be admissible, however, it does not seem an exorbitant price to pay for the saving of 9 lives in every 100 cases; for the reduction of the case mortality of typhoid by 50 per cent., especially as "the fatality of the disease......has littlealtered"under other methods of treatment. But such an admission eannot be permitted to pass. For the advantages of cold-bathing are by no means exhausted in reducing the death-rate. The objects of treatment may be summed up as follows: (I) To save life if possible, (2) to prolong it if I prove to be impossible, and (3) to obviate suffering and promote comfort in any case, even when $I$ and 2 prove to be impossible.

I have shown in The Cold-bath Treatment of Typhoid that (1) the case mortality of the disease is reduced by 50 per cent., (2) that nearly all the distressing symptoms connected with the pyrexial state, and many of those depending on the intestinal lesion, are alleviated to an extent not attainable by any other therapeutic measure, (3) that nutrition is maintained and convalescence greatly accelerated; and (4) that even in eases which terminate fatally, life is prolonged on the average by several days

The possibility of selection of cases has naturally been enter tained by all who have worked at the subject. To me it has seemed that any selection to be successful would require an almost complete foreknowledge of the course and duration of the disease in each individual case, and this at so early a stage that as yet no threatening symptoms are present. Personally I have found this quite impossible.

Dr. Phillips is of opinion that "if the temperature is not very high, is accompanied by jemissions, is not very irregular in its rises and falls, if the pulse is not very rapid or feeble, and if the patient does not seem greatly affected by toxæmia ......he might be spared the cold bath for a time at any rate." I admit that if it were possible to foresee with any approach to certainty a short duration in such a case, the omission might be occasionally made without grave risk. But there is nothing in the above description of symptoms to show that the fever will not last for many weeks, in which case much ground will have been lost irrecoverably. The omission will then appear especially regrettable, since it is in the early stage that severe refrigeration is well supported, and that most advantage is to be derived therefrom.

All who have practical experience of eold bathing are struck with the great relief to all pyrexial symptoms, the increased comfort and deep refreshing sleep which rapidly follow each immersion. None of them, therefore, could have been responsible for the statement that " the 9 who die have these repeated bathings added to their sufferings."

Dr. Phillips says of the treatment:-"Its infrequent use .......is due not so much to a doubt of its virtue as to its impracticability." This admission is most important, for it may be taken to mean that the long-standing prejudices as to the dangers of inducing shock, collapse, internal congestions, hæmorrhages, pulmonary, and other complications, are at length beginning to yield to the pressure of authentically recorded facts. It will now be chiefly necessary to deal with the mechanical difficulties of the system; and these have now been overcome at so many hospitals for so many years in different parts of the world that it can hardly be maintained that the metropolis of Great Britain is incompetent for the task. As a matter of fact, when once the system has been fairly started, the practical difficulties in hospitals, at any rate, are found to be altegether imaginary : $^{-}$The only conditions in which this is not so, are in the homes of the poor and ignorant, and it is a question whether typhoid should ever be treated in such surroundings. In the houses of the well-todo the treatment is of course perfectly easy and quite satisfactory.

REFERENCES.

1 Observations on the Treatment of Enteric Fever hy Systematic Cold Bathing in the German Hospital, Philadelphia. J. C. Wilson, p. so 2 The Cold-bath Treatment_of Typhoid, pp. 63 , ro8.

\section{SPINDLE-CELLED SARCOMA OF RECTUM.}

Excision of:Rectum, with Preservation of the Sphincter, by Subperiosteal Resection of the Coccyx and Part of the Sacrum.

BX THOMAS CARWARDINE, M.S.LoND., F.R.C.S.EnG., [Assistant Surgeon, Bristol Royal Infirmary.

SARComa of the recturn is rare. Cases of lympho-sarcoma and melano-sarcoma have been described by Ball ${ }^{1}$ and by Nepveu, and Cooper and Edwards ${ }^{2}$ record a case of mixed-celled sarcoma of the anus. I have not met with any published record of a spindle-celled sarcoma of the rectum in Great Britain, and Mr. Harrison Cripps, whose experience in rectal pathology is great, has not himself come across any sarcomatous growths..$^{3}$. Ball (Dublin) describes two specimens of spindle-celled sarcoma of the anus and rectum respectively, and Cooper and Edwards refer to a rectal case under Dr. R. J. Lewis (Pennsylvania)." In the museum of the Bristol Royal Infirmary I have come across a specimen removed by $\mathrm{Mr}$. F. R. Cross described as a spindle-celled sarcoma of the rectum, and an examination of a microscopical section confirms that diagnosis. $^{6}$

History.-J. B., a miner, aged 41, was sent to me in July last by a medical friend for what appeared to be undoubtedly cancer of the rectum. Three months previously the patient began to experience pain, difficulty, and bleeding on defæcation. The finger in the rectum detected a bleeding, fungating rosette-like mass, about $2 \frac{1}{2}$ inches long and 2 inches broad, extending over the anterior and left lateral wall, everted and thickened at the edges, ulcerated in the centre, with its lower margin about $2 \frac{1}{2}$ inches from the anus, and its upper beyond the reach of the finger. It was hard and craggy, but freely movable with the mucous membrane.

Structure of Growth.-A naked-eye section of the growth is represented in Fig. I, which shows the probable origin in the submucous tissue, its direction of growth, and its circümscribed character. The tumour was composed of glistening interlacing bundles of tissue. For a microphotograph I am

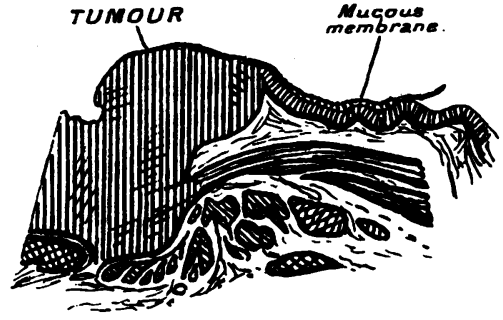

Fig. 1. - Naked eye section through edge of tumour.

indebted to my friend Dr. Jas. Taylor (Fig. 2, see p. 1812). The growth consists almost entirely of long spindle cells with a variety of oat-shaped nuclei, but here and there a large round cell or a large multinucleated cell is found.

Operation.-The method of operation presents some features of interest, and I venture to give the details on account of its facility and the excellence of its results. On July 29th left inguinal colotomy was performed in a few minutes without stitches by the method of Reclus, using a glass rod, and the gut was opened without anæesthesia a few days afterwards. This enabled the whole rectum to be flushed twice a day into a bedpan by means of a 4-pint douche of iodised water; so that at the date of operation (August gth) the bowel was as clean and sweet as possible to be, and the area was neither obscured nor fouled by fæces. 
The position was that recommended by Mr. Godlee-that is, with the buttocks projecting over the end of the table, with the left knee flexed at the side of the table resting on a stool. A clean incision was made over the coccyx and that

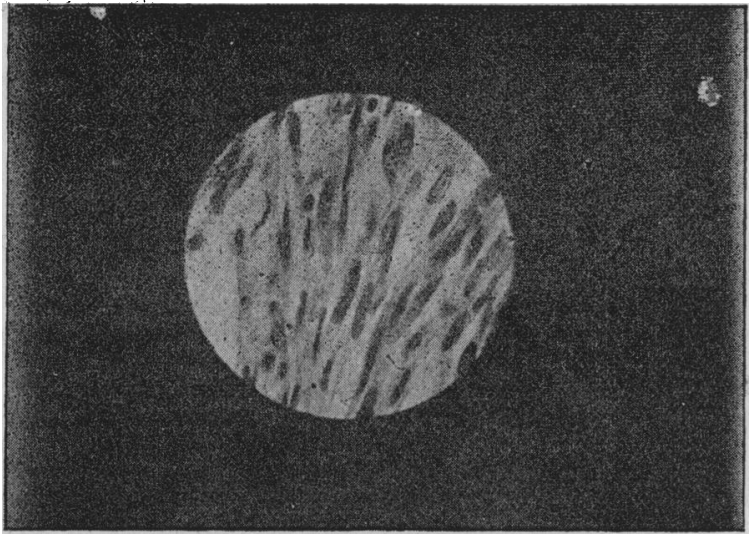

Fig. 2.

bone excised subperiosteally. The sphincter was then stretched and a sharp bistoury passed through the anus, transfixing at the upper part of the incision, and all the retro-rectal tissues cut through mesially with a rapid cut (Fig. 3). The tumour at once bulged into the wound, and it

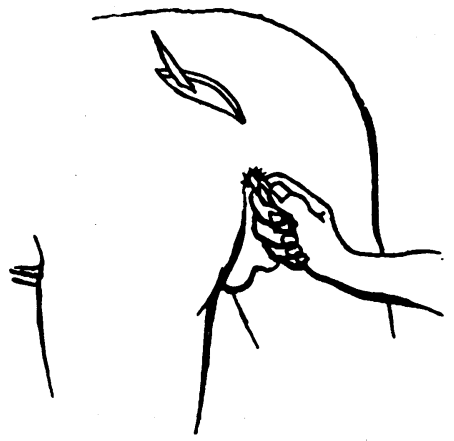

Fig. 30-Mesial retro-rectal section after subperiosteal resection of coccyx (median subperiosteal proctotomy).

was found necessary to excise the lower part of the sacrum subperiosteally. The rectum was then dissected horizontally with scissors just above the sphincter, and then on either side, the whole circumference of the bowel being raised except a narrow strip of healthy mucous membrane. The peritoneum was fully exposed for 3 inches by separation of the rectum from it, and the mucous membrane was divided transversely about $1 \frac{1}{2}$ inch above the growth (Fig. 4). This left a thick

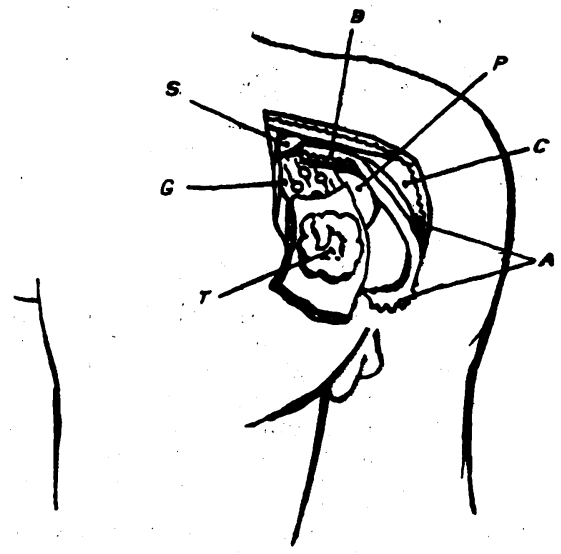

Fig. 4. -A, sphincter ani, right half ; B, bowel, upper end; c, coccyges periosteum; T. tumour: $G$, glands in presacral tissue; $s$, third p:ece of sacrum ; $P$, peritoneum. band of perirectal tissue, comprising that between the sacrum and peritoneum, in which were about a dozen enlarged glands. This tissue was separated high up into the hollow of the sacrum, where by means of a right-angled double-edged palate knife it was divided across. A few catgut sutures were applied to the mucous membrane, iodoform gauze was inserted into loose spaces, and the sacral wound stitched up with silkworm-gut sutures except for a small gauze drain below.

After-History.-After the third day the lower bowel was irrigated daily with iodine water through the lower colotomy orifice. The sacral wound healed by first intention, the stitches being removed on the ninth day. During this time the temperature touched $99^{\circ}$ on one occasion only. On August 19th, Mitchell Banks's method for reducing the colotomy spur was employed, and on August 23rd an extraperitoneal operation was done for closure of the colotomy opening. A month later rectal sensation and control returned, and continued to improve so that he was able to walk about and control his motions. When he left on October $13^{t h}$, much improved in appearance and weight, there was no sign of stricture, he had control over his fæces, and the finger in the anus was gripped by the sphincter, which exhibited muscular action on straining. The sacrum was completed, and a partial coccyx had reformed from the periosteum. A small colotomy fistula remained, and will require subsequent closure.

\section{REMARKS.}

Whilst this method, which we may call subperiosteal proctotomy, can have no disadvantages except those incidental to a preliminary colotomy, it seems to have numerous advantages, and to give great freedom of exposure without the very grave risks of Kraske's operation. Some of the advantages may be enumerated.

1. The purity and visibility of the empty and cleansed rectum, enabling all the parts to be clearly seen, and the peritoneum retracted as the dissection of the rectum from it proceeds.

2. The very free exposure of the whole, and the ability to dissect up the presaeral tissue in continuity and divide it high up.

3. The asepticity of the operation performed as described.

4. The preservation of the sphincter ani with its mucous membrane, and thus of the rectal sense with subsequent fæcal control.

5. The preservation of the nerve supply to the coccygeus levator, and sphineter ani by subperiosteal resection of the coccyx and mesial proctotomy.

6. The renewal of the bony coccyx and sacrum from the periosteum, and thus the preservation of the natural coccygeal attachments of the coccyge us, levator, and sphincter ani.

7. The satisfaction to an operating surgeon of simple, safe, clean, and complete procedure.

\section{REFERENCES.}

1 Ball, Rectum and Anus, 1894, p. 342. 2 Cooper and Edwards, Rectum and Anus, 1892, p. 206. 3 Cripps, Diseases of Rectum, 1890, p. 336. \& Ball, Op. cit., p. 342. 'SCoper and Edwards, Op. cit., p. 206. 'See also discussion, Patho logical Society, BRITIsH Medical JoURNAL, November sgth, 1898, p. 1555.

\section{MEMORANDA: \\ MEDICAL, SURGICAL, OBSTETRICAL, THERA- PEUTICAL, PATHOLOGICAL, Etc.}

\section{INTESTINAL ANTISEPTICS IN DIABETES.}

Dr. MonCKTON's memorandum on the above subject in the British Medical Journal of November igth is very interesting, and, as he has started the subject, it may be opportune to give the details of two cases treated on similar lines.

The first was our coachman, a fair-haired man of about 23 . who fainted when driving me in October, 1895 ; - I then found that he had been suffering for some weeks from neuralgia, constipation, frequent micturition, and progressive debility. He said he could hardly sit up when driving, and that a friend had been doing stable work for him. He had not named his symptoms as he was afraid of losing his situation. I found 